\title{
Application of a new wind driving force model in soil wind erosion area of northern China
}

\author{
ZOU Xueyong ${ }^{1 *}$, LI Huiru ${ }^{1}$, LIU Wei $^{2}$, WANG Jingpu ${ }^{3}$, CHENG Hong ${ }^{1}$, WU Xiaoxu ${ }^{4}$, \\ ZHANG Chunlai $^{1}$, KANG Liqiang ${ }^{1}$ \\ ${ }^{1}$ State Key Laboratory of Earth Surface Processes and Resource Ecology/MOE Engineering Research Center of Desertification \\ and Blown-sand Control, Beijing Normal University, Beijing 100875, China; \\ ${ }^{2}$ School of Geographic and Environmental Sciences, Tianjin Normal University, Tianjin 300387, China; \\ ${ }^{3}$ School of Resources and Environmental Engineering, Ludong University, Yantai 264025, China; \\ ${ }^{4}$ College of Global Change and Earth System Science, Beijing Normal University, Beijing 100875, China
}

\begin{abstract}
The shear stress generated by the wind on the land surface is the driving force that results in the wind erosion of the soil. It is an independent factor influencing soil wind erosion. The factors related to wind erosivity, known as submodels, mainly include the weather factor (WF) in revised wind erosion equation (RWEQ), the erosion submodel (ES) in wind erosion prediction system (WEPS), as well as the drift potential (DP) in wind energy environmental assessment. However, the essential factors of WF and ES contain wind, soil characteristics and surface coverings, which therefore results in the interdependence between WF or ES and other factors (e.g., soil erodible factor) in soil erosion models. Considering that DP is a relative indicator of the wind energy environment and does not have the value of expressing wind to induce shear stress on the surface. Therefore, a new factor is needed to express accurately wind erosivity. Based on the theoretical basis that the soil loss by wind erosion $(Q)$ is proportional to the shear stress of the wind on the soil surface, a new model of wind driving force (WDF) was established, which expresses the potential capacity of wind to drive soil mass in per unit area and a period of time. Through the calculations in the typical area, the WDF, WF and DP are compared and analyzed from the theoretical basis, construction goal, problem-solving ability and typical area application; the spatial distribution of soil wind erosion intensity was concurrently compared with the spatial distributions of the WDF, WF and DP values in the typical area. The results indicate that the WDF is better to reflect the potential capacity of wind erosivity than WF and DP, and that the WDF model is a good model with universal applicability and can be logically incorporated into the soil wind erosion models.
\end{abstract}

Keywords: soil wind erosion; wind driving force; weather factor; drift potential; WDF (wind driving force) model

Citation: ZOU Xueyong, LI Huiru, LIU Wei, WANG Jingpu, CHENG Hong, WU Xiaoxu, ZHANG Chunlai, KANG Liqiang. 2020. Application of a new wind driving force model in soil wind erosion area of northern China. Journal of Arid Land, 12(3): 423-435. https://doi.org/10.1007/s40333-020-0103-9

\section{Introduction}

The wind is the driving force of soil wind erosion. When the shear stress exerted on the soil surface by wind exceeds the ability of soil to resist detachment, soil wind erosion occurs (Skidmore, 1986). Therefore, wind velocity is regarded as an important variable in soil wind erosion models (Woodruff and Siddoway, 1965; Hagen et al., 1996; Fryrear et al., 1998). Since the shear stress of

\footnotetext{
*Corresponding author: ZOU Xueyong (E-mail: zouxy@bnu.edu.cn)

Received 2019-10-28; revised 2020-04-28; accepted 2020-05-06

(C) Xinjiang Institute of Ecology and Geography, Chinese Academy of Sciences, Science Press and Springer-Verlag GmbH Germany, part of Springer Nature 2020
} 
the wind on the soil surface is an important factor determining the soil loss by wind erosion, the relationship between the soil loss by wind erosion $(Q)$ and the shear stress $(\tau)$ of the wind on the soil surface is generally written as $Q \propto\left(\tau^{1 / 2}-\tau_{t}^{1 / 2}\right) \tau$ (Lettau and Lettau, 1978), or $Q \propto\left(\tau-\tau_{t}\right) \tau^{1 / 2}$ (Sauermann et al., 2001), or $Q \propto\left(\tau-\tau_{t}\right)$ (Anderson and Haff, 1988; Andreotti, 2004; Durán and Herrmann, 2006; Martin and Kok, 2017), where $\tau=\rho_{\mathrm{g}} u *, \tau_{t}=\rho_{\mathrm{g}} u * t, \tau$ and $\tau_{t}$ expressed in N/m². Here, $\tau_{t}$ is the critical shear stress when wind erosion occurs, $\rho_{\mathrm{g}}$ is the density of air $\left(\mathrm{kg} / \mathrm{m}^{3}\right)$, and $u *$ and $u *_{t}$ are the friction velocity and the critical friction velocity $(\mathrm{m} / \mathrm{s})$, respectively. When the soil wind erosion reaches steady state, $Q$ represents the soil particle flux in per unit width and unit time. Previous studies have shown that the number of soil particles $(N)$ that is driven by the wind in the unit area and unit time is also positively correlated with $\left(\tau-\tau_{t}\right)$ (Cheng et al., 2007).

Because of many factors affecting soil wind erosion, previous studies often took the factors, such as surface crop residue coverage, crop upright biomass, surface soil moisture, precipitation and evaporation, into account when describing the wind erosivity, and called wind erosivity as the weather factor (WF) (FAO et al., 1979; Hagen et al., 1996), or the erosion submodel (ES) (Hagen et al., 1996). The problem is that WF and ES do not exclusively express wind erosivity, but rather combine wind erosivity with the intrinsic properties of the soil (e.g., soil moisture) and surface attachments (e.g., crop residues) (Zou et al., 2014). In fact, wind erosivity depends on the wind velocity determined by the weather process and does not change with other factors influencing soil wind erosion. Roughness elements on the surface (such as plants and ridges) only re-transform the wind velocity of the near-surface layer. From the perspective of wind erosion dynamics, it is necessary to study the energy relationship between wind and soil, and the factors affecting soil wind erosion can be divided into air, surface and soil (Chepil, 1945). During the soil wind erosion process, the properties and mechanical attributes of each influencing factor are different. According to the attributes that are favorable or unfavorable to soil wind erosion, and the principles of similar mechanical properties exhibited during soil wind erosion process, the three categories of factors, which are air, surface roughness and soil, represent wind erosivity factors, roughness interference factors and soil anti-erodibility factors, respectively (Zou et al., 2015). Corresponding to the three categories of factors are wind driving force (WDF), roughness interference force (RIF) and soil anti-erodibility force (SAF), respectively (Zou et al., 2014). Studying the energy relationship between wind and soil is of great significance during the process of soil wind erosion (Chepil, 1945). The purpose of establishing the WDF model is to distinguish the wind driving force from soil characteristics and roughness factors affecting soil wind erosion.

Wind erosivity factors include the wind velocity, wind direction, density of air, viscosity of air and turbulence (Zou et al., 2015). In the soil wind erosion models, the WDF should be an independent variable or a submodel, which is spatially located above the soil surface, and is in contact with the surface roughness elements and soil surface. In terms of mechanical properties, the WDF reflects the potential for wind to produce shear stress on the soil surface and causes the displacement of soil particles away from their original positions (Zou et al., 2014). For a given area, soil wind erosion also has a time scale, which means that the WDF must match the unit area and time scale. Therefore, when establishing the WDF model, the focus of attention must be the accumulative shear stress generated by the wind on the surface per unit area in unit time or a given period. In general, the WDF is defined as the accumulative shear stress generated by wind on a surface per unit area in one year $(\mathrm{Pa} \mathrm{h} / \mathrm{a})$.

\section{Theoretical foundation and model establishment}

The information available in previous studies on the WDF was fragmentary and insufficient to support the establishment of the WDF model (Zou et al., 2014, 2015; Zhang et al., 2018). It was, therefore, necessary to start from the basic assumptions and their verifications.

\subsection{Hypothesis and verification}

\subsubsection{Hypothesis 1}

In each wind erosion event, the wind velocity always increases from low to high, gradually reaches 
the maximum, and then reduces. Also, the wind velocity can be considered to consist of several grades of wind velocity. Since $u *$ exhibits different intensities on soil wind erosion, the resulting values of $\tau$ will therefore differ. Consequently, in each wind erosion event, the value of $u *$ must be divided into several grades. Previous studies showed that the wind velocity variations in soil wind erosion areas in China and abroad are consistent with this assumption (Hagen et al., 1996; Fryrear et al., 1998; Yuan et al., 2018), even globally (Dai and Deser, 1999).

\subsubsection{Hypothesis 2}

The WDF model considers that the relationship between the soil loss by $Q$ and $\tau$ of the wind on the soil surface as $Q \propto\left(\tau-\tau_{\mathrm{t}}\right)$. The model also assumes that when soil wind erosion is at steady state, the soil wind erosion rate $\left(\mathrm{kg} /\left(\mathrm{m}^{2} \cdot \mathrm{s}\right)\right)$ refers to the ratio of the aeolian sand flux $(\mathrm{kg} /(\mathrm{m} \cdot \mathrm{s}))$ by the length of the plot (m), which represents the soil loss by wind erosion per unit area per unit time. In order to verify the objectivity of this hypothesis, it is necessary to start by clarifying the following two basic concepts. Firstly, Bagnold (1941) initially proposed the aeolian sand flux $Q \propto \tau^{3 / 2}$. To avoid meaningless result calculated from $Q \propto \tau^{3 / 2}$ when $\tau<\tau_{t}$, the forms of $Q \propto\left(\tau^{1 / 2}-\tau_{t}^{1 / 2}\right) \tau$ and $Q \propto\left(\tau-\tau_{t}\right) \tau^{1 / 2}$ were later proposed (Lettau and Lettau, 1978; Sauermann et al., 2001), these equations are overall expressed as $Q \propto \tau^{3 / 2}$. Secondly, In order to reveal in essence the relationship between the shear stress of the wind acting on the soil surface and the $Q$, the $Q \propto\left(\tau-\tau_{t}\right)$ form was proposed (Anderson and Haff, 1988; Andreotti, 2004; Durán and Herrmann, 2006; Martin and Kok, 2017), where $\left(\tau-\tau_{t}\right)$ was the effective instantaneous shear stress of the wind acting on the soil surface $\left(\mathrm{N} / \mathrm{m}^{2}\right)$; $Q$ was the particle mass of the soil surface that is the instantaneously driven by the wind in the unit area under the action of $\left(\tau-\tau_{t}\right)$. When the soil wind erosion is at steady state, the particle mass on the soil surface that is driven by the wind per unit area per unit time is completely transported by the wind. Therefore, the $Q$ in the aeolian sand flux equations $Q \propto \tau^{3 / 2}, Q \propto\left(\tau^{1 / 2}-\tau_{t}^{1 / 2}\right) \tau$ and $Q \propto\left(\tau-\tau_{t}\right) \tau^{1 / 2}$ divided by the length of the plot represents essentially the soil wind erosion rate.

\subsubsection{Hypothesis 3}

In the 'appropriate time scale', the soil wind erosion process is considered to be at steady state. The 'appropriate time scale' here is a variable, and its specific value is determined by the duration of monitoring soil wind erosion. For example, it can be 5 or 10 min when monitoring soil wind erosion in a day or a month in a limited area, and it can be an hour when monitoring inter-annual soil wind erosion in a large area. The point of this hypothesis is that since the wind is always in a turbulent pulsating state by nature, which may induce the soil wind erosion rate to have strong pulsating and intermittent characteristics, it is very difficult to strictly define whether or not the soil wind erosion is at steady state (Zou et al., 2019). Hence, both the wind velocity is in turbulent conditions, and aeolian sand flux have time-scale effects (Durán et al., 2011; Martin et al., 2013; Mayaud et al., 2017). This means that for a specific turbulent wind, there is a good correlation between wind velocity and aeolian sand flux in the average value of a certain time period (Butterfield, 1991, 1998, 1999; Wang and Zheng, 2013). Therefore, the so-called steady state is actually only limited to a relatively short period of time in which the soil wind erosion rate fluctuates within a small range. For the study of soil wind erosion process, the length of the time period is the decisive factor in determining the 'appropriate time scale'. Currently, the 'appropriate time scale' is usually ranges from 5 to $10 \mathrm{~min}$ (Udo, 2016; Shang et al., 2017) in a day or a few days, and an hour in the interannual time period (The Office of the First National Water Resources Census Leading Group of the State Council, 2010).

\subsubsection{Hypothesis 4}

Within a given period of time, the accumulative value of $\left(\tau-\tau_{t}\right)$ or $\tau$ is suitable for the calculation of soil loss by wind erosion. This assumption is based on the relationship $Q \propto\left(\tau-\tau_{t}\right)$, which means that $Q$ is linear with $\left(\tau-\tau_{t}\right)$ or $\tau$. The value of $\tau$ is only related to the potential capacity of the wind-driven soil surface particle mass, which reflects the potential capacity of $u *$ for soil wind erosion. However, the occurrence of soil wind erosion depends on whether the value of $\tau$ (i.e., $u *$ value) is greater than $\tau_{t}$ (i.e., $u *_{t}$ value). When $\tau>\tau_{t}$ (i.e., $\left.u *>u^{*} t\right),\left(\tau-\tau_{t}\right)$ represents the effective shear stress of the wind acting on the soil surface. Therefore, within a given period of time, the relationship between the 
cumulative value of $\left(\tau-\tau_{t}\right)$ or $\tau$ and the cumulative value of soil loss by wind erosion is not only linear, but also one-to-one correspondence. Considering the variability of $u *_{t}$ with the physical and chemical properties of soils, a fixed $u^{*}$ value cannot be given. Also, the WDF is defined as the potential capacity for the wind to produce shear stress on the soil surface and to cause the displacement of soil particles from their original position (Zou et al., 2014). Therefore, for the calculation of the WDF in this study, the accumulative value of $\tau$ was considered.

\subsection{Principles of the model establishment}

\subsubsection{Principle 1}

The WDF model is established for flat surfaces without roughness elements, as constrained by the definition of the WDF given above. From the perspective of wind erosion dynamics, the only forces acting on soil wind erosion are the WDF, RIF and SAF (Chepil, 1945; Zou et al., 2014, 2015). The WDF is an independent driving force of soil wind erosion. RIF is the re-transformation of the WDF by various roughness elements attached to the surface, which therefore weakens the WDF and acts in opposition with the space located above the soil surface. SAF is a force that the soil itself possesses against the WDF and is determined by factors including the soil physical and chemical properties, as well as the plant roots. Therefore, when establishing the WDF model, the value of aerodynamic roughness length $\left(\mathrm{z}_{0}\right)$ was considered to be $0.02 \mathrm{~mm}$, in agreement with previous studies on a flat surface (Bagnold, 1941; Dong et al., 2001; Liu et al., 2003). Using $u *$ and a fixed $\mathrm{z}_{0}$ value when applying the WDF model, the latter is therefore not subjected to the limitations of wind velocity observation heights and areas.

\subsubsection{Principle 2}

The WDF model has temporal meaning and can represent the magnitude and duration of the force of the wind acting on the soil surface. Soil wind erosion is not only related to wind velocity but also related to the action time of the wind. Under similar wind velocity conditions, the soil loss by wind erosion increases with increasing wind action time. For similar wind action time, the soil loss by wind erosion rapidly increases with the increasing wind velocity. Obviously, the wind velocity and wind action time will continuously vary in a certain period of time (hour, day, month and year). When calculating the soil loss by wind erosion, the shear stress generated by the wind on the soil surface and the wind action time is therefore used in order for the wind velocity and the wind action time to be considered simultaneously.

\subsubsection{Principle 3}

The WDF model has a theoretical basis for mechanics and contains easy-to-obtain indices. The ultimate goal of establishing the WDF model is to establish a soil wind erosion model that has a theoretical basis for wind erosion dynamics. The wind velocity and direction, temperature, air pressure and altitude included in the WDF model are the regular measurement constituents of the weather station. The density of air can be calculated based on some regular measurement constituents including the altitude of the weather station, the air temperature and the air pressure. The computation results of the WDF model represent the potential erosivity of the wind on a flat surface, considered as the maximum erosivity. When roughness elements are present on the surface, the shear stress of the wind shared by the roughness elements is calculated by the shear stress partition model. The maximum shear stress, the average shear stress and the shear stress distribution actually received on the soil surface can also be calculated by the shear stress partition model (Raupach, 1992; Raupach et al., 1993; Raupach et al., 2006; Walter et al., 2012), while these three shear stresses on the soil surface are not considered in this paper.

\subsection{Model}

Based on the above assumptions and principles, in a soil wind erosion event, for a certain $u *_{i}$ level, the shear stress generated per unit area of the soil surface is:

$$
\tau_{i}=\rho_{\mathrm{g}} u_{*_{i}}^{2},
$$

where $u *_{i}$ represents the $i^{\text {th }}$ friction velocity level $(i=1,2, \ldots, n$, i.e., each soil wind erosion event 
contains $n$ friction velocity levels). Generally, $u *_{i}$ is graded at intervals of $0.034 \mathrm{~m} / \mathrm{s}$, which corresponds to a level of $1.0 \mathrm{~m} / \mathrm{s}$ wind velocity interval at the height of $10 \mathrm{~m}$ of a weather station. When using the wind velocity data observed by the weather station, $u *_{i}$ is calculated using the formula $u_{i} / u_{*_{i}}=\ln \left(z / \mathrm{z}_{0}\right) / \mathrm{k}$, where $u_{i}$ is the wind velocity observed by the weather station; $z$ is the height at which the wind velocity is observed; $\mathrm{k}$ is the Von Karman constant, which generally takes a value of 0.4 ; and $\mathrm{z}_{0}=0.02 \mathrm{~mm}$. The mass of soil particles driven by wind per unit area of the soil surface is $q_{i} \propto u *_{i} t_{i}$ due to the $u *_{i}$ level, where $t_{i}$ is the duration of the $u *_{i}$ level. For a soil wind erosion event, the total amount of soil particle mass $q\left(\mathrm{~kg} / \mathrm{m}^{2}\right)$ driven by wind in the unit area of the soil surface is the sum of all $q_{i}$ values such that $q=\sum_{i=1}^{n} q_{i}$.

In classical mechanics, an impulse represents an increment of the momentum of an object subjected to the influence of resultant of external forces. In other words, it is the physical quantity that represents the accumulative effect of the resultant of external forces on the object over a certain time period, and is the reason for change of the mechanical motion state of the object. Since the physical meaning of impulse is completely consistent with the physical meaning that the WDF is required to express according to the principles for the model establishment, the impulse can, therefore, be used to express the WDF. Theoretically, during the $j^{\text {th }}$ soil wind erosion event, the function that the $u *$ changes with time can be given as $u *=f(T)$, and consequently $\mathrm{WDF}_{j}=\int_{t=0}^{t=T} \rho_{g} f^{2}(T) d T$, where $T(\mathrm{~s})$ is the duration of the $j^{\text {th }}$ soil wind erosion event. It nonetheless remains difficult to give an accurate expression of $f(T)$ in practical applications, which renders more convenient the application of discretized $u *_{i}$. Thus, for a specific $u *_{i}$ level, the $\mathrm{WDF}_{i}$ generated on the soil surface per unit area is $\mathrm{WDF}_{i}=\tau_{i} t_{i}$. In a soil wind erosion event, the total $\mathrm{WDF}_{j}$ generated on the soil surface per unit area by all levels of $u *_{t}$ is $I_{j}=\sum_{i=1}^{n} \tau_{i} t_{i}$, where $j$ represents a given $j$ th soil wind erosion event $(j=1,2, \ldots, m)$ occurring within a certain time period. Hence, if $m$ wind erosion events occur within a given time period, $\mathrm{WDF}=\sum_{j=1}^{m} I_{j}$.

In practical applications, the value of $u *_{t}$ can be accurately determined for a given study area. When relating the WDF to the calculation of soil loss by wind erosion, the condition $u *_{i} \geq u *_{t}$ should be satisfied for each value of $u_{* i}$ in order to eliminate the impacts of the data of $u *_{i}<u *_{t}$ on the WDF calculation results in the process of calculating the value of the WDF.

\section{Application of the WDF model}

\subsection{Application area}

The application area $\left(32^{\circ} 07^{\prime} 12^{\prime \prime}-49^{\circ} 20^{\prime} 24^{\prime} \mathrm{N}, 75^{\circ} 08^{\prime} 24^{\prime \prime}-126^{\circ} 34^{\prime} 48^{\prime \prime} \mathrm{E}\right)$ of the WDF model is about $3.95 \times 10^{6} \mathrm{~km}^{2}$. Soil wind erosion occurs the most frequently in this part of China (Ministry of Water Resources of China and National Bureau of Statistics of China, 2013). The annual average wind velocity in this area is $2.6 \mathrm{~m} / \mathrm{s}$. The annual average wind velocity has obviously spatial differences, the maximum value of annual average wind velocity is $8.6 \mathrm{~m} / \mathrm{s}$ (Fig. 1). This area presents an annual mean air temperature of about $6.0^{\circ} \mathrm{C}$, a mean annual precipitation of $291 \mathrm{~mm}$ and a mean annual surface snow cover days of around $45 \mathrm{~d}$.

\subsection{Data}

The data used in this paper included the altitude of the weather stations, wind velocity, wind direction, air temperature, atmospheric relative humidity, precipitation, ground temperature $(0 \mathrm{~cm})$ and snow cover. The time series ranges from 1980 to 2016. The wind velocity, wind direction, daily air temperature, daily atmospheric relative humidity, daily precipitation and daily ground 
temperature were derived from 157 weather stations in the application area (Fig. 1).

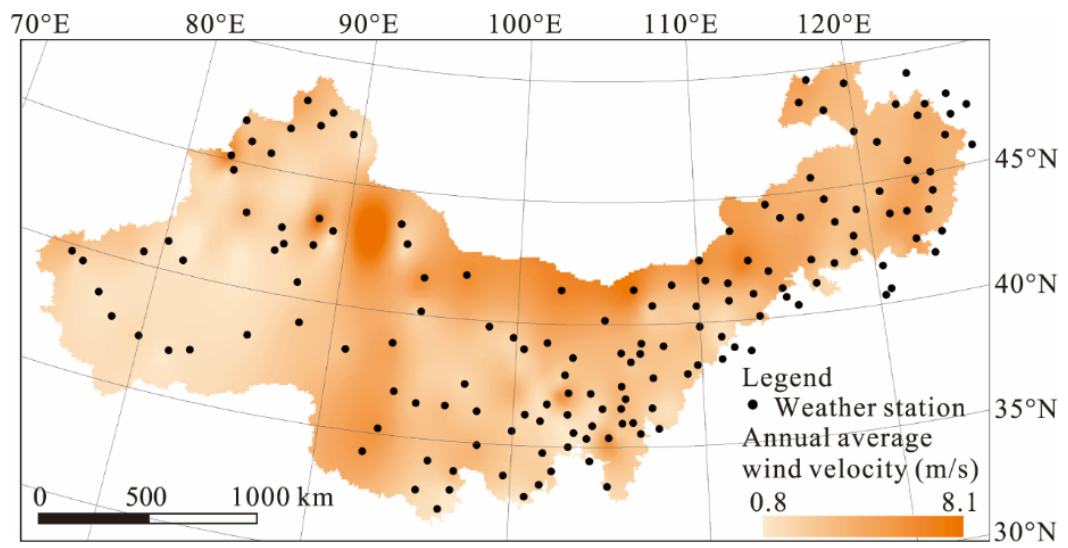

Fig. 1 Application area of the WDF model and the spatial distributions of meteorological stations and annual average wind velocity

There are two sources of wind velocity and wind direction data. One source is the first National Water Conservancy Census on Wind Erosion Census group (Zou et al., 2012), with time series from 1 January 1980 to 31 December 2009. Another source is the National Meteorological Information Center, with time series from 1 January 2010 to 31 December 2016. Both data sources provided hourly data of $u *$ and wind direction. The accuracy of the wind velocity measurement was $0.1 \mathrm{~m} / \mathrm{s}$, and the wind direction was 16 directions.

The data of daily air temperature, atmospheric relative humidity, precipitation and ground temperature were from the Dataset of Daily Ground Climate Data in China (v3.0), which was provided by the National Meteorological Information Center. The time series ranges from 1 January 1980 to 31 December 2016. The measurement accuracies of the daily average air temperature and the ground temperature, daily average atmospheric relative humidity and daily precipitation were $0.1^{\circ} \mathrm{C}, 1 \%$ and $0.1 \mathrm{~mm}$, respectively.

There are two sources of snow cover data. The first source was from the long-term snow depth dataset of China (1979-2014) (http://westdc.westgis.ac.cn/heihe) published by the Cold and Arid Regions Sciences Data Center at Lanzhou. The second was from the accumulative days of monthly snow cover provided by the National Meteorological Information Center. These two sources provided daily snow cover data.

In this paper, each year represented a given time period when applying the FDF model. The time interval between wind velocity level and wind direction division was set to $1 \mathrm{~h}$. The divided time intervals of temperature, atmospheric relative humidity, precipitation and ground temperature were set to $1 \mathrm{~d}$. The hourly value of the WDF was calculated by using hourly wind velocity data, and the daily value of the WDF was after that derived by accumulating the WDF over $24 \mathrm{~h}$ per day. The daily actual air density $\left(\rho_{\mathrm{g}}, \mathrm{kg} / \mathrm{m}^{3}\right)$ can be calculated through Equations $2-4$.

$$
\begin{gathered}
\rho_{\mathrm{g}}=\rho_{0} T_{0} P /\left(P_{0} T\right), \\
P=101.08 \mathrm{e}^{(-H / 7924)}, \\
T=273+t,
\end{gathered}
$$

where $\rho_{0}$ is the air density under standard conditions and is equal to $1.293 \mathrm{~kg} / \mathrm{m}^{3} ; T_{0}$ is the air thermodynamic temperature under standard state and is equal to $273 \mathrm{~K} ; P$ is the actual atmospheric pressure $(\mathrm{kPa})$, which varies with the altitude (Wang, 1984); $P_{0}$ is the standard atmospheric pressure and its value is $101.3 \mathrm{kPa} ; H$ is the altitude $(\mathrm{m})$; and $t$ is the daily average temperature $\left({ }^{\circ} \mathrm{C}\right)$. The data above were all spatial interpolation with Kriging interpolation method.

\subsection{Application results}

In the application area of the WDF model, the WDF generally indicated a downward trend. The 
Mann-Kendall trend test (Mann, 1945; Kendall and Gibbons, 1990) results showed that 1988 was the mutation time point (confidence interval of $\alpha<0.05$ ). During the period 1980-1988, the WDF rapidly decreased from 234.54 to $179.04 \mathrm{~N} \mathrm{~h} / \mathrm{m}^{2}$. During the period 1989-2016, there was a fluctuating slow downward trend. The range of the WDF varied from 103.70 to $154.86 \mathrm{~N} \mathrm{~h} / \mathrm{m}^{2}$ (Fig. 2).

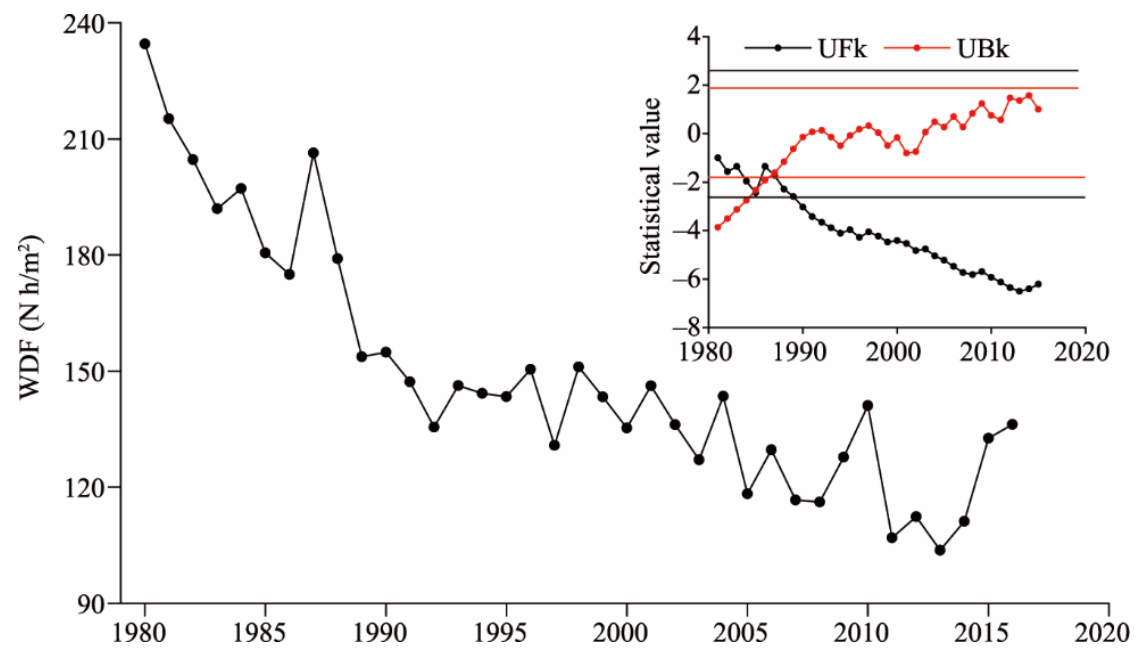

Fig. 2 Annual variation of the WDF values and the Mann-Kendall trend test (in the upper-right corner) in the application area during 1980-2016

The WDF in every season showed a downward trend during the period from 1980 to 2016, but the WDF value changed significantly in different seasons (Fig. 3). The WDF value in spring was significantly greater than in the other seasons, and its decreasing rate was also significantly greater than that in the other seasons. The WDF value in spring decreased rapidly from 112.10 to $81.39 \mathrm{~N}$ $\mathrm{h} / \mathrm{m}^{2}$ during 1980-1988, and the annual average decline rate reached $3.16 \mathrm{~N} \mathrm{~h} / \mathrm{m}^{2}$. However, the annual average decline rates of the WDF values during this period were only $1.25,1.67$ and 0.72 $\mathrm{N} \mathrm{h} / \mathrm{m}^{2}$ in summer, autumn and winter, respectively. During 1989-2016, the change of the WDF value in each season slowed down. The change of the WDF value in spring ranged from 48.85 to $78.03 \mathrm{~N} \mathrm{~h} / \mathrm{m}^{2}$ with an average of $64.26 \mathrm{~N} \mathrm{~h} / \mathrm{m}^{2}$. The average values of the WDF in summer, autumn and winter were $31.65,30.17$ and $30.20 \mathrm{~N} \mathrm{~h} / \mathrm{m}^{2}$, respectively.

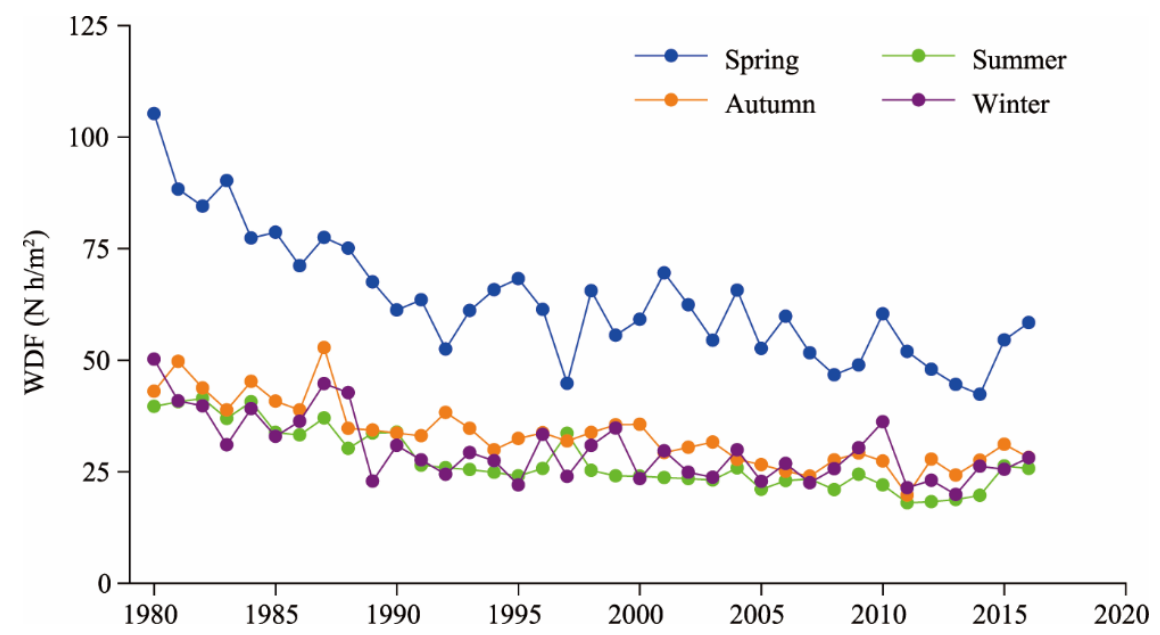

Fig. 3 Seasonal variation of the WDF values in the application area during 1980-2016

In the model application area, the multi-year average of the WDF was $149.43 \mathrm{~N} \mathrm{~h} / \mathrm{m}^{2}$, the median value was $109.00 \mathrm{~N} \mathrm{~h} / \mathrm{m}^{2}$, and about $2 / 3$ of the application area was smaller than the median value 
(Fig. 4). In the spatial distribution, the high-value areas of the multi-year average WDF value were mainly distributed in the north and southwest of the central part of the model application area, where the maximum value reached $744.71 \mathrm{~N} \mathrm{~h} / \mathrm{m}^{2}$. Also, the low-value areas of the WDF were mainly distributed in southwestern and the southeastern part of the model application area, and the lowest value was distributed in southwestern part of the model application area, and was only 4.49 $\mathrm{N} \mathrm{h} / \mathrm{m}^{2}$. Based on the Mann-Kendall nonparametric statistical method (Mann, 1945; Kendall and Gibbons, 1990), the trend of the WDF was tested. The positive value of the parameter Zc means that the general trend is increasing, and the negative value of $Z \mathrm{c}$ means that the general trend is decreasing. The results indicated that the $Z \mathrm{c}$ high-value areas were mainly distributed in the north of the central part of the model application area, as well as southwest of the central part of the model application area, which meant that the WDF exhibited an increasing trend in these areas. Similarly, the Zc negative values demonstrated that the WDF presented a decreasing trend in southwestern part of the model application area.
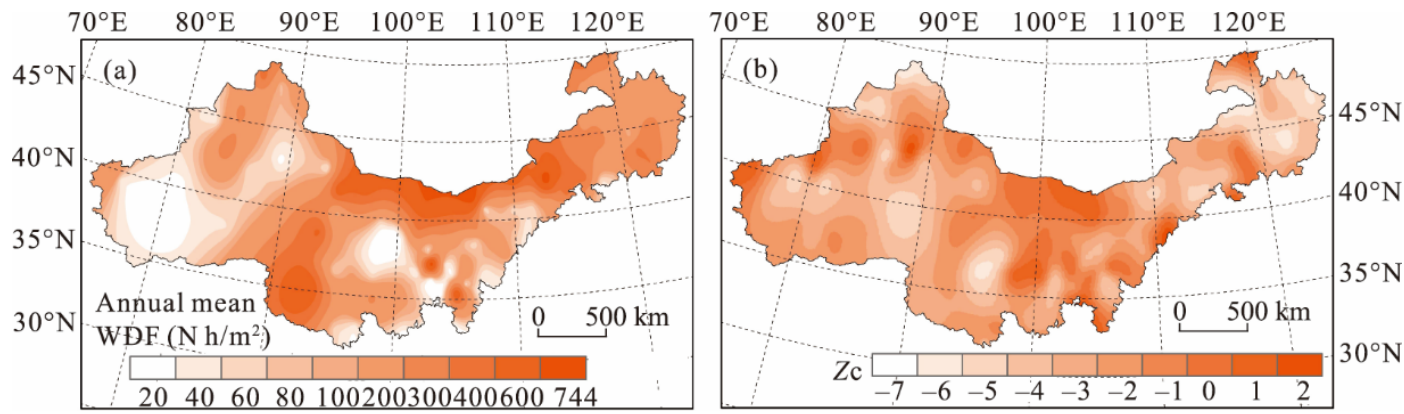

Fig. 4 Spatial distribution of annual mean WDF value (a) and Mann-Kendall trend test (b) in the application area during 1980-2016

The WDF values of each season were similar to the annual mean WDF values in spatial distribution (Fig. 5). The highest and average WDF values of spring, summer, autumn, and winter were 259.55 and $63.41,166.03$ and $27.52,163.71$ and 28.55 , and 237.99 and $29.88 \mathrm{~N} \mathrm{~h} / \mathrm{m}^{2}$, respectively.
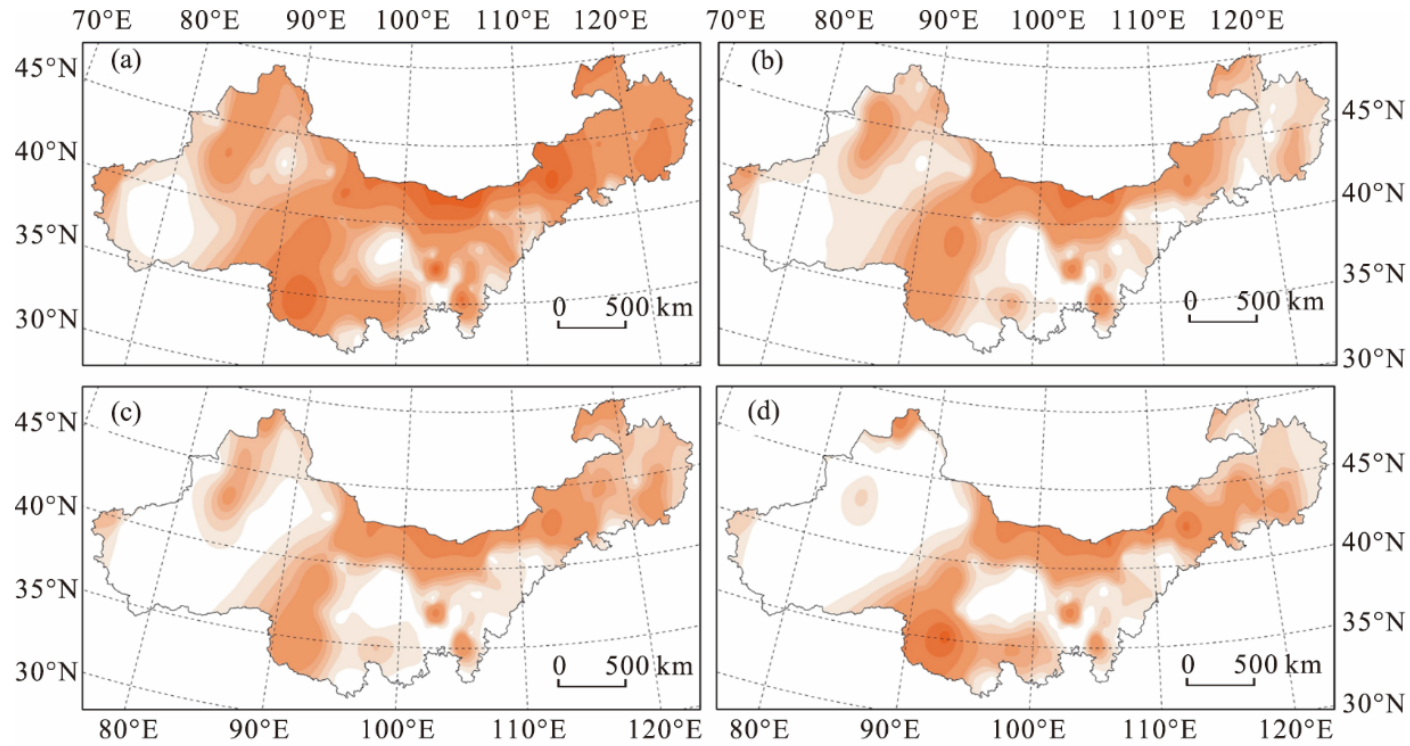

Seasonal mean WDF $\left(\mathrm{N} \mathrm{h} / \mathrm{m}^{2}\right)$

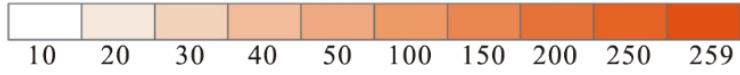

Fig. 5 Spatial distribution of seasonal mean WDF value in the application area in spring (a), summer (b), autumn (c) and winter (d) during 1980-2016 


\section{Discussion}

\subsection{Rationality of the WDF model}

There are a large number of factors affecting wind erosion that noticeably increases the complexity of soil wind erosion research. Amongst these influencing factors, some are favourable and will promote soil wind erosion, while others are unfavourable and will have a rather inhibitory effect. The wind is the only factor that plays a positive role in promoting soil wind erosion (Skidmore, 1986). The WDF proposed herein has a clear physical meaning and contains not only the force of the wind acting on the soil surface but also the duration of this force, which is essentially the impulse generated by the wind on the soil surface per unit area and its duration. However, the physical meaning of other parameters related to the WDF currently in use is not clear. For example, WF in the revised wind erosion equation (RWEQ) is expressed in $\mathrm{kg} / \mathrm{m}$ (Fryrear et al., 1998), and the unit of the drift potential (DP) expressing the wind energy environment is in the cubic of per nautical mile per hour, that is (n mile/h) ${ }^{3}$ (Fryberger and Dean, 1979).

The simple use of the wind velocity or $u *$ to express the erosion ability of wind on the soil surface is not comprehensive, because $\rho_{g}$ changes significantly due to the impacts of air temperature and altitude, which may affect the calculation result of $\tau$. From 1980 to 2016, in soil wind erosion areas in northern China, the monthly average $\rho_{g}$ value ranged between 1.01 and $1.14 \mathrm{~kg} / \mathrm{m}^{3}$, the daily $\rho_{g}$ value ranged between 0.71 and $1.36 \mathrm{~kg} / \mathrm{m}^{3}$. It can be seen that the variation range of $\rho_{g}$ value is very large at different time. The WDF model can justly reflect the change of $\rho_{g}$ and $u *$, as well as wind erosivity, but WF and DP cannot.

In addition, from the perspective of wind erosion dynamics, wind erosivity should be an independent variable in the soil wind erosion model, it is only related to the relevant characteristics of air (Chepil, 1945; Zou et al., 2014; Zou et al., 2015), but the wind cannot be mixed with certain soil characteristics. The purpose of establishing the WDF model is to achieve this goal, and overcome the shortage that the wind velocity is mixed with certain soil properties in WF and ES (Hagen et al., 1996; Fryrear et al., 1998).

\subsection{Other parameters related to the WDF}

The parameters directly related to the WDF are WF and DP. Among them, the calculation equation of WF is (Fryrear et al., 1998):

$$
\begin{aligned}
& \mathrm{WF}=\mathrm{Wf} \times \mathrm{SW} \times \mathrm{SD} \times \rho_{\mathrm{g}} / \mathrm{g}, \\
& \mathrm{Wf}=\frac{N_{d}}{N} \sum_{i=1}^{N}\left(U_{i}\left(U_{i}-U_{t}\right)^{2}\right),
\end{aligned}
$$

where Wf is called the wind factor $(\mathrm{m} / \mathrm{s})^{3} ; \mathrm{SW}$ and SD are respectively called the soil wetness factor and the snow cover factor which are dimensionless, with values varying within the range of $0-1$; SW can be estimated based on potential evaporation, precipitation, irrigation, and the number of days of precipitation and irrigation (Fryrear et al., 1998), or based on average air temperature and relative humidity (Cheng and Cheng, 1980; Dong and Kang, 1994); $\rho_{\mathrm{g}}$ is the dry air density, which is usually equal to $1.29 \mathrm{~kg} / \mathrm{m}^{3}$; and $\mathrm{g}$ is the gravitational acceleration $\left(9.8 \mathrm{~m} / \mathrm{s}^{2}\right)$. When calculating $\mathrm{Wf}, U_{i}$ is the $i^{\text {th }}$ observed wind velocity $(\mathrm{m} / \mathrm{s})$ at the height of $2 \mathrm{~m}$ above the ground. When $U_{i}<5$ $\mathrm{m} / \mathrm{s}, \mathrm{Wf}=0 ; U_{t}$ is the critical wind velocity of soil wind erosion $(\mathrm{m} / \mathrm{s})$ at the height of $2 \mathrm{~m}$ above the ground with a value of $5 \mathrm{~m} / \mathrm{s} ; N$ is the number of wind velocity observations in a time period of 1$15 \mathrm{~d}(N \geq 500) ; N_{d}$ is the number of days in the observation period (Fryrear et al., 1998, 2000). It can be seen from Equations 5 and 6, the core idea of WF is an expression of wind erosivity established on the basis of the equation of aeolian sand flux proposed by Bagnold (1941) and Zingg (1953), but mixes with the factors other than wind, which caused WF to not really express potential erosivity of wind.

The purpose of proposing DP was to use the reliable ground wind information to study the formation and evolution of sand dunes (Fryberger and Dean, 1979), and the theoretical basis of DP is based on the equation of aeolian sand flux proposed by Lettau and Lettau (1978). The calculation 
equation of DP is:

$$
\mathrm{DP}=\sum_{i=1}^{n}\left(W_{i} V_{i}^{2}\left(V_{i}-V_{t}\right) t_{i}\right)
$$

where $n$ is the total number of different wind velocity levels, which are divided into five levels; $i$ is one of the five wind velocity levels $(i=1,2, \cdots, 5) ; W_{i}$ is the weight of the $i^{\text {th }}$ wind velocity level; $V_{i}$ is the $i$-level wind velocity representative value (n mile/h) at the height of $10 \mathrm{~m}$ above the ground; $V_{t}$ is the critical wind velocity (n mile/h) at the height of $10 \mathrm{~m}$ above the ground; $t_{i}$ is the frequency $(\%)$ of the $i^{\text {th }}$ wind velocity level. When calculating DP, different weights are assigned to different $V_{i}$ (Fryberger and Dean, 1979; Pearce and Walker, 2005), which simplifies the equation of aeolian sand flux proposed by Lettau and Lettau (1978). DP is a substitution index of the wind energy environment. It can only indicate the relative strength of the aeolian sand flux and does not have the value of expressing potential erosivity of wind. It cannot be applied in the soil wind erosion model.

\subsection{Comparison of wind erosion intensity and the WDF in a typical area}

To further compare the differences in the WDF, WF and DP in the expression of wind erosivity, WF and DP were additionally calculated in the Taklimakan Desert and its surrounding areas in the west part of the soil wind erosion area in northern China. The reason why this area was selected is that the terrain is relatively flat, the soil moisture content is generally low, and there are very little roughness elements on the ground (e.g., vegetation). In other areas, the soil wind erosion intensity can be significantly affected by mountains, vegetation and precipitation, which is not conducive to distinguish the impacts of wind erosivity on soil wind erosion intensity. Figure 6 indicates that the WDF is the best fitted with soil wind erosion intensity in spatial distribution, DP is moderately, and WF is the worst. The west part of the Taklimakan Desert is affected by the loose sediments of the dry lake basin and represents a higher level of soil wind erosion intensity, which is slightly different from the performance of the WDF. In the calculation of DP, the weight $\left(W_{i}\right)$ of the wind velocity level is artificially added, the higher the wind velocity level, the greater the weight, which results in the differences between the maximum and minimum values of DP to be improperly enlarged. Moreover, the spatial distributions of DP value and soil wind erosion intensity showed opposite trends in the most areas of surrounding Taklimakan Desert.

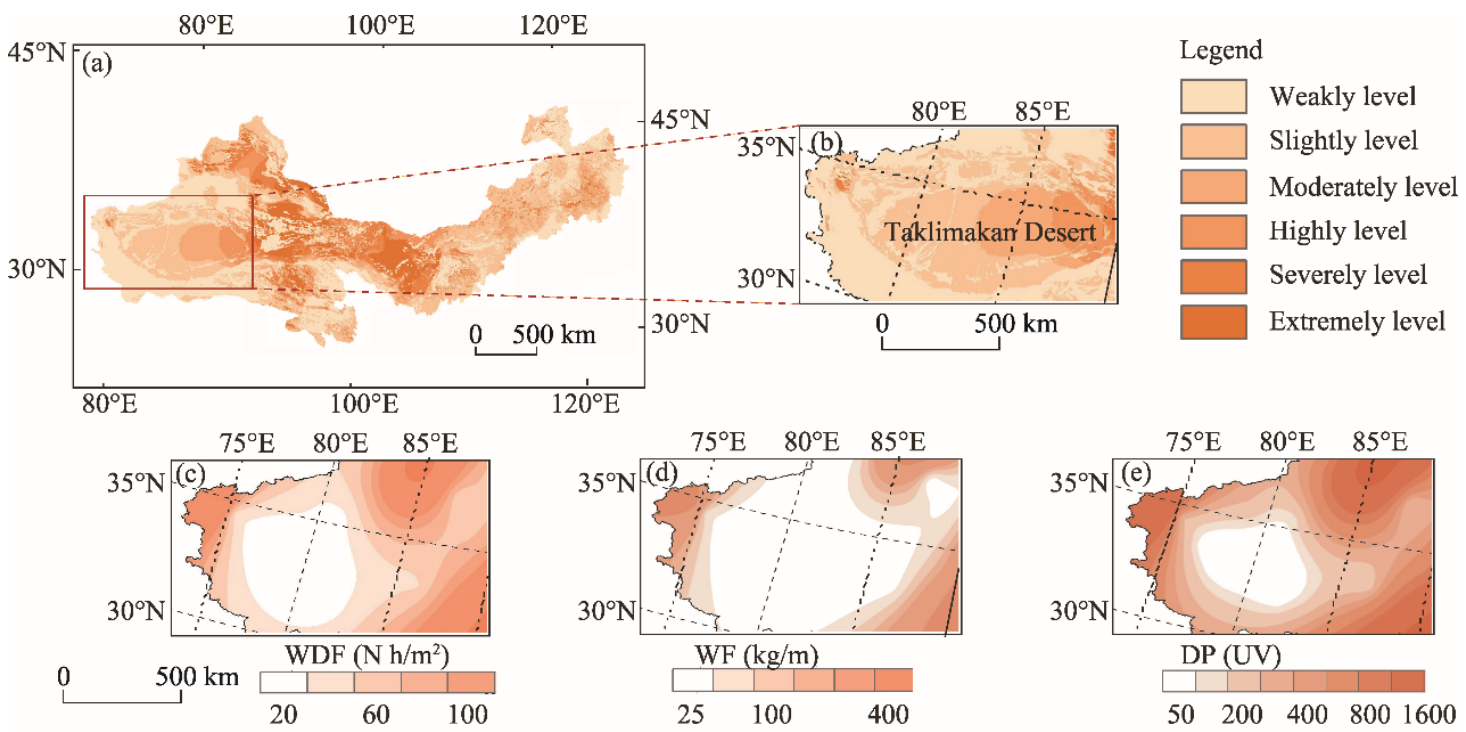

Fig. 6 Spatial distribution comparison of soil wind erosion intensity with the WDF, WF (weather factor) and DP (drift potential) in the typical area (Taklimakan Desert and its surrounding areas). (a), spatial distribution of soil wind erosion intensity modified from the literature (Niu, 2017); (b), a scale enlarged view of the typical area; (c), (d) and (e), the spatial distributions of the WDF, WF and DP in the typical area, respectively. 


\section{Conclusions}

In the existing soil wind erosion models, the factor or called submodel expressing wind erosivity is not independent variable, which makes the theoretical basis of these models unreliable. Each soil wind erosion event is a random event that occurs within a certain period of time. The WDF model is a variable in the soil wind erosion model, which is a type of random event. The independence of random events is a unique and very important concept in probability theory. The theoretical basis for establishing any model is that several variables should be independent of each other. According to the definition, the WDF does not depend on any other influencing factors of soil wind erosion; that is, the WDF model is an independent variable. Therefore, it meets the modeling requirements of the soil wind erosion model, and overcomes the limitations that WF and ES present in combining wind and soil moisture as well as crop residues (Hagen et al., 1996; Fryrear et al., 1998).

From the perspective of the earth surface material cycle process, which contains three links of erosion, transportation and deposition, erosion is the first link. As a type of soil erosion, soil wind erosion should not include the process that the eroded soil particles are transported and deposited by the wind. Therefore, it is defined as 'the process of wind force causing the topsoil particles to detach the original spatial position' (Zou et al., 2014). The difference between soil wind erosion and soil loss by wind is that the latter is a concept with time and spatial scale (Zou et al., 2015), which not only reflects the results of wind erosion but also shows the transportation and settlement results of the eroded particles (Zhang et al., 2018). In this paper, based on the theoretical basis of $Q \propto \tau$, the WDF model precisely expresses the potential capacity of soil particle mass per unit area to be driven by the wind in a certain period of time.

The WDF model was established under the theoretical framework of the dynamic models of soil wind erosion (Zou et al., 2015) and had a clear physical meaning rather than a statistical model based on experimental data. Because the WDF, RIF and SAF were strictly distinguished, all the three are independent of each other. The WDF can be logically incorporated into the soil wind erosion model and is more applicable than WF, ES and DP. The comparison results of spatial distributions of the WDF, WF and DP with that of soil wind erosion intensity in the typical area are strong evidences (Fig. 6). In practical applications, for an area where $u_{*}{ }_{t}$ can be determined, in order to eliminate the impacts of the data of $u *_{i}<u *_{t}$ on the WDF calculation results, $u *$ values of $\geq u *_{t}$ are selected to participate in the calculation of the WDF. The WDF model lays a reliable theoretical foundation for the establishment of the dynamic models of soil wind erosion.

\section{Acknowledgements}

This work was supported by the National Natural Science Foundation of China (41330746, 41630747). Thanks to Professor WANG Zhoulong from Ludong University for his assistance in data processing. The authors thank anonymous reviewers and the editors for their suggestions on improving the manuscript.

\section{References}

Anderson R S, Haff P K. 1988. Simulation of eolian saltation. Science, 241(4867): 820-823.

Andreotti B. 2004. A two-species model of aeolian sand transport. Journal of Fluid Mechanics, 510: 47-70.

Bagnold R A. 1941. The Physics of Blown Sand and Desert Dunes. London: Methuen Company, 1-265.

Butterfield G R. 1991. Grain transport rates in steady and unsteady turbulent airflows. Acta Mechanica, (Suppl. 1): 97-122.

Butterfield G R. 1998. Transitional behaviour of saltation: wind tunnel observations of unsteady wind. Journal of Arid Environment, 39(3): 377-394.

Butterfield G R. 1999. Application of thermal anemometry and high-frequency measurement of mass flux to aeolian sediment transport research. Geomorphology, 29(1-2): 31-58.

Cheng H, Zou X, Zhang C. 2007. A study of the number of sand grains lifting off per unit time and per unit sand bed area. Journal of Geophysical Research: Atmospheres, 112(D15), doi: 10.1029/2006JD007641.

Cheng T, Cheng W. 1980. The Methods of Determination and Calculation of Evaporation and Evaporation Forces in Farmland. Geographical Symposium, No. 12. Beijing: Science Press, 74-83. (in Chinese) 
Chepil W S. 1945. Dynamics of wind erosion: I. Nature of movement of soil by wind. Soil Science, 60(4): 305-320.

Dai A, Deser C. 1999. Diurnal and semidiurnal variations in global surface wind and divergence fields. Journal of Geophysical Research: Atmospheres, 104(D24): 31109-31125.

Dong Y, Kang G. 1994. Study on the wind erosion climatic erosivity in arid and semi-arid areas in China. Journal of Soil and Water Conservation, 8(3): 1-7. (in Chinese)

Dong Z, Wang X, Zhao A, et al. 2001. Aerodynamic roughness of fixed sandy beds. Journal of Geophysical Research: Solid Earth, 106(B6): 11001-11011.

Durán O, Herrmann H. 2006. Modelling of saturated sand flux. Journal of Statistical Mechanics: Theory and Experiment, (7): P07011. doi: 10.1088/1742-5468/2006/07/P07011.

Durán O, Claudin P, Andreotti B. 2011. On aeolian transport: Grain-scale interactions, dynamical mechanisms and scaling laws. Aeolian Research, 3(3): 243-270.

FAO (Food and Agriculture Organisation), UNEP (United Nations Environment Programme), UNESCO (United Nations Educational Scientific and Cultural Organization). 1979. A provisional methodology for soil degradation assessment. Rome: FAO, 1-84.

Fryberger S G, Dean G. 1979. Dune forms and wind regime. In: McKee E D. A Study of Global Sand Seas. Washington: Geological Survey and United States National Aeronautics and Space Administration, 137-169.

Fryrear D W, Saleh A, Bilbro J D, et al. 1998. Revised Wind erosion equation. In: Wind Erosion and Water Conservation Research Unit, USDA-ARS, Technical Bulletin No. 1, 1-175.

Fryrear D W, Bilbro J D, Saleh A, et al. 2000. RWEQ: improved wind erosion technology. Journal of Soil and Water Conservation, 55(2): 183-189.

Hagen L J, Wagner L E, Tatarko J. 1996. Wind erosion prediction system (WEPS). Technical Documentation. Wind Erosion Research Unit, USDA-ARS, 213-216.

Kendall M G, Gibbons J D. 1990. Rank Correlation Methods (5 ${ }^{\text {th }}$ ed.). London: Edward Arnold, 1-260.

Lettau K, Lettau H. 1978. Experimental and micrometeorological field studies of dune migration. In: Lettau K, Lettau H. Exploring the World's Driest Climate. Madison: University of Wisconsin-Madison, 110-147.

Liu X, Dong Z, Wang X. 2003. Aerodynamic roughness of fixed sandy beds. Journal of Desert Research, 23(2): 111-117. (in Chinese)

Mann H B. 1945. Nonparametric tests against trend. Econometrica, 13(3): 245-259

Martin R L, Barchyn T E, Hugenholtz C H, et al. 2013. Timescale dependence of aeolian sand flux observations under atmospheric turbulence. Journal of Geophysical Research: Atmospheres, 118(6): 9078-9092.

Martin R L, Kok J F. 2017. Wind-invariant saltation heights imply linear scaling of aeolian saltation flux with shear stress. Science Advances, 3(6): e1602569. doi: 10.1126/sciadv.1602569.

Mayaud J R, Bailey R M, Wiggs G F S, et al. 2017. Modelling aeolian sand transport using a dynamic mass balancing approach. Geomorphology, 280: 108-121.

Ministry of Water Resources of China, National Bureau of Statistics of China. 2013. Bulletin of First National Census for Water (bilingual version in Chinese and English). Beijing: China Water \& Power Press, 1-20.

Niu C H. 2017. Census Report on Soil and Water Conservation. Beijing: China Water \& Power Press, 213-218. (in Chinese)

Pearce K I, Walker I J. 2005. Frequency and magnitude biases in the "Fryberger" model, with implications for characterizing geomorphically effective winds. Geomorphology, 68(1-2): 39-55.

Raupach M R .1992. Drag and drag partition on rough surfaces. Boundary-Layer Meteorology, 60: 375-395.

Raupach M R, Gillette D A, Leys J F. 1993. The effect of roughness elements on wind erosion threshold. Journal of Geophysical Research: Atmospheres, 98(D2): 3023-3029.

Raupach M R, Hughes D E, Cleugh H A. 2006. Momentum absorption in rough-wall boundary layers with sparse roughness elements in random and clustered distributions. Boundary-Layer Meteorology, 120: 201-218.

Sauermann G, Kroy K, Herrmann H J. 2001. Continuum saltation model for sand dunes. Physical Review E, 64(3): 031305. doi: 10.1103/PhysRevE.64.031305.

Shang H, Yin Z, Zhang P, et al. 2017. Characteristics of wind velocity fluctuation over Gobi underlying surface. Journal of Nanjing Forestry University (Natural Sciences Edition), 4(1): 123-128. (in Chinese)

Skidmore E L. 1986. Wind erosion climatic erosivity. Climatic Change, 9: 195-208.

The Office of the First National Water Resources Census Leading Group of the State Council. 2010. The Sixth Volume of Training Hand Book of the First National Census for Water: The Survey of Soil and Water Conservation. Beijing: China Water \& Power Press, 94-118. (in Chinese)

Udo K. 2016. Wind turbulence effects on dune sand transport. Journal of Coastal Research, 75(Suppl.1): $333-337$. 
Walter B, Gromke C, Lehning M. 2012. Shear-stress partitioning in live plant canopies and modifications to Raupach's model. Boundary-Layer Meteorology, 144: 217-241.

Wang B. 1984. Discussion on the variation of annual average pressure with altitude in plateau area of China. Automobile Technology, (1): 10-16. (in Chinese)

Wang P, Zheng X. 2013. Fluctuating of wind-blown sand flux in field wind condition. Journal of Desert Research, 33(6): 16221628. (in Chinese)

Woodruff N, Siddoway F H. 1965. A wind erosion equation. Soil Science Society of America Journal, 29(5): 602-608.

Yuan Y, Yin S, Xie Y, et al. 2018. Temporal and spatial characteristics of diurnal variations of wind speed in wind erosion areas over China. Arid Land Geography, 41(3): 480-487. (in Chinese)

Zhang C, Song C, Wang Z, et al. 2018. Review and prospect of the study on soil wind erosion process. Advances in Earth Science, 33(1): 27-41. (in Chinese)

Zingg A W. 1953. Wind tunnel studies of the movement of sedimentary material. In: Proceedings of the $5^{\text {th }}$ Hydraulic Conference, Iowa City: Iowa Institute of Hydraulic, 111-135.

Zou X, Zhang C, Cheng H, et al. 2014. Classification and representation of factors affecting soil wind erosion in a model. Advances in Earth Science, 29(8): 875-889. (in Chinese)

Zou X, Zhang C, Cheng H, et al. 2015. Cogitation on developing a dynamic model of soil wind erosion. Science China: Earth Sciences, 58(3): 462-473.

Zou X, Zhang M, Zhang C, et al. 2019. Response of aeolian flux to soil particle properties and airflow turbulence fluctuation. Advances in Earth Science, 34(8): 787-800. (in Chinese) 